\title{
TLR8 and TLR9 Polymorphisms and Pulmonary Tuberculosis
}

\author{
Saeedeh Salimi ${ }^{1,2, *}$ \\ ${ }^{1}$ Cellular and Molecular Research Center, Zahedan University of Medical Sciences, Zahedan, IR Iran \\ ${ }^{2}$ Department of Clinical Biochemistry, School of Medicine, Zahedan University of Medical Sciences, Zahedan, IR Iran \\ *Corresponding author: Saeedeh Salimi, Department of Clinical Biochemistry, School of Medicine, Zahedan University of Medical Sciences, Zahedan, IR Iran. Tel: +98-5413425728, \\ E-mail: sasalimi@yahoo.com
}

Received: June 5, 2015; Accepted: June 20, 2015

Keywords: Toll Like Receptor 8; Toll Like Receptor 9; Polymorphisms; Pulmonary Tuberculosis

\section{Dear Editor}

Tuberculosis is principally caused by Mycobacterium tuberculosis and is an infectious disease, confirmed as a global health problem worldwide. Every year more than nine million individuals are affected by Tuberculosis (TB) and nearly 1.7 million deaths have been reported as a result of this devastating disease. The incidence of TB in Iran was reported to be approximately 13.7 per 100000 individuals in 2009; yet TB incidence in the Sistan and Baluchestan province in southeastern Iran, was greater due to its proximity to high incidence countries. In 2009, TB incidence was 109.7 per 100000 individuals in the northern regions of this province compared to 36.6 per 100000 in the southern regions $(1,2)$. It is believed that the incidence and severity of TB is higher in some populations, which could be due to genetic susceptibility to the pathogen and adverse socio-economic factors (3). The higher risk of TB in identical twins compared to nonidentical twins confirms a host genetic susceptibility for this disease. In addition, understanding the molecular mechanisms that cause protective immunity is a necessary step in the development of improved therapies and vaccines for TB (3).

Different case-control studies investigated candidate genes in affected populations and have identified several possible susceptibility genes. Toll-like receptors (TLRs) have been defined as a class of pattern recognition molecules whose function is to recognize a wide variety of ligands, which are known as pathogen-associated molecular patterns (PAMPs). These ligands include a broad range of microbial molecules including proteins, nucleic acids, lipids, or synthetic chemicals. Since expression of genes involved in the inflammatory process could be induced by TLRs, these molecules play crucial roles in initiating and directing the adaptive immune system (4).

These receptors, which play important roles in the innate immune system, are located on the cell surface or subcellular membranes and are expressed in the host immune system including macrophages and dendritic cells (DCs), as well as non-immune cells. Upon activation, TLRs initiate the expression of host genes in specific signaling cascades to regulate innate and adaptive immunity (5).

Up to now, thirteen TLR members (TLR1 - TLR13) have been recognized in humans; each of them identifies various PAMPs from different microbial pathogens of bacterial, viral, fungal and protozoan origin (6). Among different TLRs, TLR1, TLR2, TLR4, TLR5, TLR6 and TLR11 are located on the cell surface, however TLR3, TLR7, TLR8 and TLR9 are localized on subcellular membranes. It seems that TLR1, TLR2, TLR4, TLR6, TLR8 and TLR9 are involved in the recognition of mycobacterium (6).

In addition, according to the role of the host genetics on TB susceptibility, various studies investigated the possible association of TLRs polymorphisms and TB (7).

During 2014, in the April issue of Gene, Cell and Tissue journal, Hashemi-Shahri et al. (8) evaluated the association between TLR8 rs3764880 A/G (MetiVal) and TLR9 rs148805533 (14bp Ins/Del) polymorphisms and Pulmonary Tuberculosis (PTB) in an Iranian population from the southeastern region of the country, as an endemic region of $\mathrm{TB}$.

They recruited 160 Pulmonary Tuberculosis patients and 160 unrelated healthy subjects in their study. They used tetra amplification refractory mutation system polymerase chain reaction (TARMS PCR) for detection of TLR8 rs3764880 polymorphism and the polymerase chain reaction (PCR) method for TLR9 rs148805533 polymorphisms. They found no association between TLR8 rs148805533 polymorphism and Pulmonary Tuberculosis neither in their female nor in their male patients. In addition, they did not observe the Del allele of $14 \mathrm{bp}$ Ins/Del polymorphism of TLR9 gene in the studied population and reported no association between this poly-

Copyright (c) 2015, Zahedan University of Medical Sciences. This is an open-access article distributed under the terms of the Creative Commons Attribution-NonCommercial 4.0 International License (http://creativecommons.org/licenses/by-nc/4.0/) which permits copy and redistribute the material just in noncommercial usages, provided the original work is properly cited. 
morphism and Pulmonary Tuberculosis (8). In contrast to the findings of Hashemi-Shahri et al. (8), Davila et al. (7) reported a correlation between TLR8 rs3764880 polymorphism and PTB in Russian and Indonesian males. Futhermore, in another study, it was showed that TLR8 rs3764880 could play a role in the modulation of TLR8dependent microbicidal response of infected macrophages. Dalgic et al. (9) found a strong correlation between TLR8 rs3764880 polymorphism and pulmonary TB susceptibility in male children. In a study performed in southern Punjab of Pakistan, the G allele of TLR8 rs3764880 A/G polymorphism was introduced as a risk factor for TB susceptibility (10). Since TLR8 is located on the $\mathrm{X}$ chromosome, the sex-dependent association between TLR8 polymorphism and TB was predictable. Nevertheless, the results of the study by Hashemi-Shahri et al. (8) were different from most other reports, which could be due to different ethnic groups living in southeast Iran; nonetheless, their findings were valuable and present new data about host genetic and environmental factors that affect TB predisposition. Although several studies revealed the association between TLR9 rs352139, rs187084 polymorphisms and TB (11-13), similar to the results of Hashemi-Shahri et al. (8), there was no association between TLR9 rs148805533 (14 bp Ins/ Del) polymorphism and TB in south India (14). However, the study of Hashemi-Shahri et al. (8) had some deficits; firstly, they did not explain the reason behind the differences between their results and those reported by other studies about the correlation between TLR8 rs3764880 polymorphism and TB. Secondly they did not mention the limitations of their study.

In summary, according to the inconsistent results, other studies on various populations should be performed to evaluate previous findings and new investigations about the association between other TLRs poly- morphisms are necessary to study the genetic basis of $\mathrm{TB}$ in southeast Iran.

\section{References}

1. World Health Organization.. Global tuberculosis control: WHO report 2010.: World Health Organization; 2010.

2. Prevention CfDCa.. Reported tuberculosis in Sistan and Balouchestan, Iran.Atlanta, GA, USA: CDC; 2009.

3. Malik S, Schurr E. Genetic susceptibility to tuberculosis. Clin Chem Lab Med. 2002;40(9):863-8.

4. Kawasaki T, Kawai T. Toll-like receptor signaling pathways. Front Immunol. 2014;5:461.

5. Kawai T, Akira S. Pathogen recognition with Toll-like receptors. Curr Opin Immunol. 2005;17(4):338-44.

6. Skevaki C, Pararas M, Kostelidou K, Tsakris A, Routsias JG. Single nucleotide polymorphisms of Toll-like receptors and susceptibility to infectious diseases. Clin Exp Immunol. 2015;180(2):165-77.

7. Davila S, Hibberd ML, Hari Dass R, Wong HE, Sahiratmadja E, Bonnard C, et al. Genetic association and expression studies indicate a role of toll-like receptor 8 in pulmonary tuberculosis. PLoS Genet. 2008; (10):e1000218.

8. Hashemi Shahri S, Taheri M, Gadri A, Naderi M, Bahari G, Hashemi M. Association Between TLR8 and TLR9 Gene Polymorphisms and Pulmonary Tuberculosis. Gene Cell Tissue. 2014;1(1):18316.

9. Dalgic N, Tekin D, Kayaalti Z, Cakir E, Soylemezoglu T, Sancar M. Relationship between toll-like receptor 8 gene polymorphisms and pediatric pulmonary tuberculosis. Dis Markers. 2011;31(1):33-8.

10. Bukhari M, Aslam MA, Khan A, Iram Q, Akbar A, Naz AG, et al. TLR8 gene polymorphism and association in bacterial load in southern Punjab of Pakistan: an association study with pulmonary tuberculosis. Int Immunogenet. 2015;42(1):46-51.

11. Chen Z, Wang W, Liang J, Wang J, Feng S, Zhang G. Association between toll-like receptors 9 (TLR9) gene polymorphism and risk of pulmonary tuberculosis: meta-analysis. BMC Pulm Med. 2015;15:57.

12. Torres-Garcia D, Cruz-Lagunas A, Garcia-Sancho Figueroa MC, Fernandez-Plata R, Baez-Saldana R, Mendoza-Milla C, et al. Variants in toll-like receptor 9 gene influence susceptibility to tuberculosis in a Mexican population.J Transl Med. 2013;11:220.

13. Kobayashi K, Yuliwulandari R, Yanai H, Naka I, Lien LT, Hang NT, et al. Association of TLR polymorphisms with development of tuberculosis in Indonesian females. Tissue Antigens. 2012;79(3):190-7.

14. Selvaraj P, Harishankar M, Singh B, Jawahar MS, Banurekha VV. Toll-like receptor and TIRAP gene polymorphisms in pulmonary tuberculosis patients of South India. Tuberculosis (Edinb). 2010;90(5):306-10. 